\title{
Cooptação e a Ética Empresarial
}

\author{
Margareth Fernandes \\ Universidade Severino Sombra, Curso de Superior de Tecnologia em \\ gestão Pública e Curso de Administração \\ fernandes.meg@Gmail.Com \\ Jesimar da Cruz Alves \\ Universidade Severino Sombra e Curso de Administração \\ jesimar.alvesegmail.com \\ João Carlos da Silva Soares \\ Universidade Severino Sombra, Mestrado Profissional \\ em Ciências Ambientais \\ joaotonidandel@gmail.com \\ Regina Aurora Marques Silva \\ Universidade Severino Sombra - Mestrado Profissional \\ em Ciências Ambientais \\ marquesesilva@yahoo.com.br
}

\begin{abstract}
Resumo: O artigo amplia o entendimento da cooptação e a ética empresarial. A cooptação dá nome a um conjunto de situações nas quais, frequentemente, as pessoas se envolvem no decorrer das atividades empresariais. Mesmo sem perceber, geralmente a cooptação é intencional e consciente: é quando se sabe exatamente o que se está querendo e fazendo; é quando se assume o papel principal de sujeito ou de objeto nas relações empresariais de acordo com os interesses pessoais, vontades e objetivos.
\end{abstract}

Palavras-chave: Cooptação. Ética. Empresa.

\section{Co-optation and Ethics in Management}

\begin{abstract}
The paper extends the understanding of co-optation and Ethical Companies. The co-option names a number of situations in which people often engage in the course of business activities. without even realizing it, often co-optation is intentional and conscious: it is when you know exactly what is wanting and doing, is when it assumes the role of subject or object in business relations according to personal interests, desires and goals.
\end{abstract}

Keywords: Co-optation. Ethics. Company. 


\section{Introdução}

Embora a cooptação envolva questões relativas à necessidade que a organização tem de que seus funcionários aceitem acriticamente as mudanças propostas pela cúpula decisória, é preciso que os funcionários internalizem os conceitos de integração, cooperação, colaboração, motivação, trabalho em equipe, adaptação às necessidades da organização, cuidado com a imagem da organização, pró-atividade e responsabilização.

A condução das mudanças propostas são importantes para o bem estar físico e psíquico do funcionário, que, de uma forma geral, interferem na capacidade de entendimento das mudanças ocorridas dentro da empresa.

\section{A Ética Empresarial}

\section{Conceito e evolução histórica}

A ética empresarial, segundo Moreira (1999), pode ser reconhecida como sendo um conjunto de preceitos morais e de responsabilidade social dentro de uma sociedade empresária. Considerando que uma das características das sociedades empresárias no desempenho de suas atividades é o lucro, desde longa data surgiu a desconfiança da eventual impossibilidade de conciliar suas atividades com a ética.

Em consonância com o fato de as sociedades empresárias serem uma organização lucrativa, pairaram, por muito tempo, o silêncio e o aceitamento da sociedade em geral de que as empresas desenvolvessem suas atividades sem qualquer preocupação ou cobrança relativas à ética.

Entretanto, desde o século XVII, o tema vem suscitando inúmeras aspirações e foi Adam Smith o precursor da ética na empresa, quando divulgou em sua obra "A Riqueza das nações" a demonstração de que o empreendedor poderia, sim, ter uma justa remuneração, consignando ainda, a possibilidade de esse lucro operar uma função social de melhorias para as empresas e, inclusive, para o bem estar da sociedade, através da geração de empregos e suas respectivas remunerações.

Nota-se nascerem, daí, os primórdios da responsabilidade social das empresas, e, considerando as ideologias de Adam Smith, as primeiras demonstrações de possibilidade real de conciliação entre ética e empresa.

Contudo, foi necessário que décadas se passassem, para que princípios éticos fossem agregados à realidade das sociedades empresariais, com a preconização de dever a empresa atuar de forma transparente, buscando sempre contribuir para o desenvolvimento comunitário e praticando a cidadania e a responsabilidade social e a ambiental.

Diante da iniciativa de Adam Smith, já no século XVII, a sociedade não se quedou silente, pois, com o passar dos tempos, exigiram-se das organizações empresarias que suas atividades fossem desenvolvidas com ética e respeito moral. 
Em 1890, foi publicada a lei a norte americana denominada "Sherman Act de 1890" e, em 1977, publicou-se a lei americana "Foreign Corrupt Practices Act (FCPA)”, proibindo a corrupção e a troca de favores com autoridades estrangeiras. Esses foram os primeiros passos, consagrados pela lei, em defesa da ética empresarial.

Um exemplo que se traz à colação foi a própria Revolução Industrial, iniciada na Europa, que alavancou os princípios dos direitos do trabalhador e, aqui, no Brasil, se tornou mais efetiva entre 1912 e 1926. Entretanto, foi a partir da Revolução de 1933, quando ocorreu a queda da Primeira República, que realmente houve toda uma mudança no comércio brasileiro, repercutindo-se nas organizações empresarias.

Em 1972, a Organização das Nações Unidas organizou em Estocolmo (Suécia) a Primeira Conferência Mundial sobre Meio Ambiente, na qual, dentre outros temas, foi concebido um debate informal a respeito da ética. $\mathrm{O}$ evento ressaltou as preocupações das organizações para com o meio ambiente e a importância de se impor vigilância, visando à preservação do planeta e de seus recursos naturais e estabelecendo princípios éticos aplicáveis às atividades empresariais.

\section{A Introdução da Ética Empresarial no Brasil e sua Repercussão Legal}

Logo após a Revolução Industrial e a reforma política do Brasil de 33, as relações comerciais no país exigiam mudanças em seus paradigmas. E, nesse sentido, conforme preconiza Arruda (2003), os primeiros passos em direção à ética empresarial foram dados através de inúmeros debates ocorridos na década de 60 , onde se pretendia elevar o trabalhador à condição de participação nos conselhos de administração.

Nota-se que, em 1941, na primeira faculdade de administração do Brasil, foram iniciados os estudos sobre a Ética Empresarial. Já nos anos 90, surgiu a implementação da ética nas empresas através de constante campanha e ações do Instituto Brasileiro de Análises Sociais e Econômicas (IMBASE), sociedade sem fins lucrativos, dedicada à pesquisa e ao estudo.

Moreira (2002) enfoca que já existe no país, certa consciência social que clama por ética na empresa e, da mesma forma, enfatiza que há um ambiente jurídico que demonstra e exige um comportamento ético; um exemplo está na crescente defesa dos direitos do consumidor.

Diante deste diapasão, nortearam-se instrumentos jurídicos dedicados ao tema, como as leis de Responsabilidades Fiscais, do Código de Defesa do Consumidor, das Leis Extravagantes e, a partir do advento da introdução do Novo código Civil Brasileiro em 2002, o tema passou a ter mais ênfase em conjunto com alguns institutos doutrinários, como a punição pela prática de assédio moral, de improbidades administrativas, de coação moral e física, dentre inúmeros outros institutos.

\section{A Ética Empresarial no Limiar jurídico}

Com o apoio da mídia internacional, nota-se que, em todos os países do globo, tem sido crescente a pressão social no interesse de que as empresas adotem práticas éticas, baseadas na lei e na moral. 
No Brasil não é diferente; embora a preocupação específica com o tema seja recente, existem muitos textos legais e regulamentares que já foram promulgados, principalmente durante as últimas três décadas, visando a conter práticas antiéticas em diversos setores e aspectos dos relacionamentos das empresas.

E, nesse sentido, temos como exemplos o Código Penal Brasileiro (lei 2848 de 1940) que define os crimes de corrupção, a Lei 8884/93 que reprime o abuso de poder econômico, o Código de Defesa do Consumidor (Lei 8078/90), a Lei das Patentes (Lei 9279/96), a Lei dos Crimes Ambientais (Lei 9605/98), a lei que protege a Propriedade Intelectual (Lei 9609/98), o Código Civil Brasileiro, as Leis Tributárias, os Códigos de Éticas profissionais, dentre outros.

Contudo, nota-se que, além das imposições legais, a sociedade surge com pressão que vem chamando a atenção das entidades de classe e de outras Organizações Não Governamentais (ONG's) e, inclusive de universidades de Administração de Empresas que em conjunto vem atuando e divulgando esse tema.

De acordo com Teixeira (1998), uma abordagem que merece atenção é de que os agentes que se relacionam internacionalmente tem sentido, mais que os outros, as imposições econômicas e jurídicas para que se comportem de acordo com os preceitos éticos, sejam eles decorrentes da aplicação dos princípios morais, sejam eles informados pelo ideal de justiça, ou sejam, aqueles determinados pelos princípios legais.

Considere-se que a empresa ética não interfere na autodeterminação dos povos. Não permite que seus registros, livros e documentos sejam usados pelo governo de um país para obter dados sobre outro governo.

Diante do exposto, a ética empresarial exigequea empresa se comportecomresponsabilidade social em qualquer local em que atue e que observe as leis e os regulamentos relativos à proteção da saúde e segurança das pessoas e à preservação do meio ambiente; que somente desenvolva atividades que envolvam perigo para a coletividade mediante controle dos riscos, nas circunstâncias em que essa coletividade aprovar a sua assunção, à vista das vantagens que obterá e que não participe de práticas ilícitas e que colabore com as autoridades no combate a elas, como, por exemplo, na luta contra a lavagem de dinheiro

\section{A Cooptação}

\section{A cooptação na empresa}

A cooptação abrange temas relativos à obrigação que a empresa tem, de fazer com que seus colaboradores não acolham negativamente as alterações sugeridas pela direção geral da empresa. Essa situação é necessária para que os colaboradores disseminem alguns conceitos, como integração, cooperação, colaboração, motivação, trabalho em equipe e a adaptação às necessidades da empresa.

A integração solicita aos funcionários a criação de "laços de confiança e respeito" e, através da cooptação, os treinamentos apelam para a noção de equilíbrio sistêmico, uma vez que, para a organização prosperar, os funcionários precisam "relacionar-se melhor", solucionando os conflitos sempre a favor do equilíbrio organizacional. A essência do 
conflito, que é a luta dinâmica dos contrários, é ignorada. Ora, como ensina Dejours (1999a , p. 76), "não se prescreve cooperação, ela depende da vontade das pessoas". Além disso, os funcionários são chamados ainda a desenvolver "a capacidade de autoestima e motivação, fator primordial para serem bem sucedidos dentro da organização".

De fato, o processo de motivação é diretamente conectado ao desempenho, pois o sujeito motivado é aquele que produz para a sua organização. $O$ trabalho em equipe é outro ponto reforçado nos treinamentos. É preciso que os funcionários adotem uma postura de querer fazer, e não de ter de fazer, visando ao aperfeiçoamento do trabalho em equipe, visando o estabelecimento de relações mais saudáveis, autênticas e produtivas.

Os treinamentos possuem como objetivo principal dar oportunidade aos participantes de conscientização das funções e responsabilidades inerentes ao seu papel profissional. Os conteúdos giram em torno de noções como: a empresa é você, responsabilizando os funcionários pelo serviço. É certo que a responsabilidade desejada pela organização é apenas, e tão somente, aquela de natureza técnica, instrumental, organizacional, que trata da eficiência e da produtividade, e não uma responsabilidade política, cívica, social ou psíquica, como expõe Enriquez (1997b, p. 12).

É importante ressaltar que os treinamentos voltados à cooptação atingem funcionários de todos os níveis hierárquicos (em que pese o foco ser o funcionário subalterno, mesmo os gerentes são submetidos à uma tentativa de condicionamento para aceitação das mudanças). Dos funcionários, espera-se que se adaptem às mudanças exigidas pela organização e a eles cabe apenas seguir as determinações e apresentar resultados.

\section{A Cooptação Competitiva: suas Técnicas e a Ética}

Nota-se que as empresas desenvolveram, ao longo dos anos, uma consubstancial obsessão pela questão da eficiência, eficácia, efetividade e desempenho. Para Chanlat (1996), essa preocupação com a rentabilidade, com a eficácia, a eficiência e a produtividade acima de tudo, acaba reduzindo o ser humano a mero recurso, a uma coisa, a uma peça da engrenagem. Mesmo as abordagens que se dizem mais "humanas" terminam caindo na armadilha da eficácia como o fim último da organização, e, sem perceber, propõem a mesma ideologia do sucesso.

É preciso, no entanto, observar que o processo de transmissão ideológica promovido pelos treinamentos estratégico/comportamentais da cooptação, não reina absoluto sobre o consciente e o inconsciente dos funcionários, uma vez que as organizações não conseguem sempre captar a seu favor a vida psíquica do sujeito, pois fazendo-o herói, ela pode suscitar-lhe uma verdadeira vocação heróica, que o levará a questionar as normas da organização. Cumpre notar, ainda, que tais treinamentos ideológicos vem recebendo muita ênfase nos últimos anos.

A cooptação conforme Doz e Hamel (2000, p. 04) refere-se ao sentido de transformar potenciais fragilidades em aliados, ou aliar pessoas com competências complementares, tornando-os parceiros, potencialmente atraentes, indisponíveis para as empresas concorrentes. Nesse sentido, lança mão de instrumentos visando à busca de estratégias internas a fim de consolidar a pacificação de seus procedimentos. 
No sentido de coespecialização, a cooptação é a criação de valor através da sinergia de recursos, posições, habilidades e fontes de conhecimentos, antes isolados, que, em conjunto, tornam-se mais valiosos, considerando como foco principal a expressão dos conceitos da empresa.

Já no sentido de aprendizagem e internalização, a cooptação refere-se a novas habilidades. Nas alianças de cooptação internas a participação dos funcionários é uma prioridade, além das capacidades diferenciadoras e ativos estratégicos singulares, haja vista que o objetivo dessa aliança é obter estratégias comportamentais diferenciadas na empresa (DOZ \& HAMEL, 2000).

Ainda de acordo com Doz e Hamel (2000), na categoria de ensino de técnicas de cooptação, há treinamentos predominantemente direcionados a funcionários que ocupam cargos de chefia. Aqui, busca-se capacitar tais funcionários no manejo dos mais diversos truques gerenciais: técnicas de ensino (ensino-aprendizagem, andragógica, aprendizagem cooperativa, didático - pedagógica); técnicas de comunicação; técnicas de resolução, administração e negociação de conflitos; técnicas de administração de mudanças; técnicas de motivação; técnicas de liderança (papel do chefe) criação de equipes e como administrar. Para uma crítica epistemológica as consultorias de cunho funcionalista-sistêmico, vem contrapondo-se as intervenções psico sociológicas, como sendo um capital intelectual e, marginalizando a ética.

Os chefes são treinados para melhor compreender os funcionários (como motivar, como comunicar, como liderar) para que sejam mais eficientes em sua manipulação. Busca-se capacitar os chefes a melhor enfrentar os problemas relacionados à gestão de pessoas, ou seja, a idéia é capacitar o chefe a gerir pessoas, como se fossem fatores de produção a serem organizados e melhor aproveitados no processo produtivo, corroborando essas técnicas com a marginalização da ética nos processos evolucionista das organizações.

Alguns treinamentos chegam a demonstrar de forma antietica, um gráfico de correlação para argumentar que o líder compreensivo tem maior controle sobre o liderado do que o líder coercitivo. Trata-se aqui das técnicas de grid gerencial, as quais fazem parte daquilo que Faria (1985b, p. 127) chama de "pacote repleto de fantasias", já que ignoram questões como gestão, exploração e distinção entre trabalho intelectual e manual.

Entretanto, o que se propõe é que o líder use uma "luva de veludo" (FARIA, 1985) para disfarçar o punho de ferro do autoritarismo organizacional. Aliás, a própria utilização de termos como líder e liderado já admite a clivagem na organização e instala rótulos que buscam ocultar a dominação de um grupo sobre outro. Interessante notar que as técnicas de comunicação ensinadas aos chefes são técnicas gerencialistas, pautadas em uma comunicação entre sujeito e objeto.

A cooptação através do ato de comunicar tem uma única direção e consiste em manipular e modificar o comportamento e, neste caso a aceitação das regras e objetivos da organização. Nesse sentido, a empresa estaria buscando tornar-se a organização estratégica a que se refere Enriquez (1997c, p. 26), pois em tais organizações "a comunicação estratégica deve ser afirmativa. Ela deve exprimir a capacidade do indivíduo de colocar e resolver os problemas, sua vontade inabalável para fazê-lo, e deve melhorar a coesão e rendimento da 
equipe". Essa argumentação indica que os comunicadores ou facilitadores da organização precisam ser grandes matadores frios.

Os treinamentos da categoria "matador frio" são aqueles que exigem que os funcionários, tanto os chefes quanto os subordinados, saibam conviver com a pressão permanente de estar sempre correspondendo ao que deles se espera. Nesse sentido, a empresa busca tornar-se uma organização estratégica, a que Enriquez (1997c, 2000-2002) se refere, uma organização que exige sujeitos vencedores, realizadores, capazes de auto-superação, que busquem constante aprendizado, que transponham todos os desafios, privações e adversidades, que deixem uma marca indelével de seu trabalho e de seu dinamismo, enfim, que sejam indivíduos matadores frios.

Percebe-se que esses treinamentos buscam utilizar os conhecimentos e habilidades adquiridas para melhor desempenho de suas funções. Dito de outro modo, o que de fato importa é o desempenho, a eficiência, a ação prática, o pragmatismo. Nesse sentido, o funcionário é apenas um meio para que os objetivos organizacionais sejam atingidos para conseguir sobreviver no mercado cada vez mais competitivo e conquistando novos clientes.

Pode-se observar a forte preocupação dos treinamentos em moldar o comportamento dos funcionários para torná-los submissos e acríticos, obtendo com isso maior facilidade para a implantação de suas diretrizes e objetivos. O sucesso da organização passa, portanto, pela mortificação do eu de seus funcionários. Afinal, como um dos próprios treinamentos Ora, se os treinamentos restringem-se a ensinar como fazer melhor na prática, se se limitam a um pragmatismo exacerbado que resulta na formação de indivíduos acríticos, ou heterônomos, (Castoriadis, 1982), se não incentiva o funcionário a pensar, a refletir sobre suas condições na realidade onde vive, acaba criando seres amorfos e submissos, indivíduos e não sujeitos

\section{A Hierarquia organizacional e a Cooptação}

Em termos gerais, o conceito de hierarquia designa uma forma de organização de diversos elementos de um determinado sistema, em que cada um deles é subordinado ao elemento que lhe está imediatamente acima.

O conceito de hierarquia é também amplamente aplicado à gestão das organizações para designar a cadeia de comando que se inicia nos gestores de topo e segue até aos trabalhadores não gestores, passando sucessivamente por todos os níveis da estrutura organizacional. É, portanto, através da hierarquia que se estabelecem as relações de autoridade formal entre superiores e subordinados e que é definida a estrutura organizacional em qualquer organização.

Assim, a estrutura organizacional é baseada no sistema de relacionamentos entre seus papéis e alguns papéis requerem pessoas para supervisionar o comportamento de outras. Uma pessoa responsável por supervisionar o desempenho de outra possui autoridade sobre essa outra pessoa. Autoridade é o poder para ter responsabilidade sobre as ações de outras pessoas e para tomar decisões relacionadas ao uso de recursos da organização.

Quando um indivíduo entende claramente as responsabilidades de seu papel como 
supervisor, o resultado é o controle, ou a habilidade para coordenar e motivar as pessoas a trabalhar para o interesse da organização. Na maioria das organizações, as pessoas que possuem papéis similares são agrupadas em subunidades, sendo funções e divisões as subunidades principais.

E, para melhor compreensão de conflitos relacionados à hierarquia organizacional, é necessário possuir uma visão ampla das inúmeras possibilidades de sua ocorrência, além de identificar até quando o conflito é saudável ou prejudicial à organização. Para Robbins (2002, p. 185), o conflito no ambiente organizacional se dá pela divergência entre os indivíduos dentro de uma estrutura hierárquica, que, por meio de suas posições, dividem opiniões díspares, as quais podem comprometer o alcance dos objetivos da organização e ocorre quando uma das partes percebe que a outra parte afeta, ou pode afetar, negativamente, alguma coisa que a primeira considera importante.

Considerando os conflitos numa organização, a cooptação vem como instrumento relevante de pacificação, uma vez que discorre, inclusive, sobre temas comportamentais. Pode-se caracterizar o processo da cooptação como uma ferramenta de vantagem competitiva, tanto interna quanto externa, ou como estratégia. A administração estratégica engloba uma série de conceitos, modelos e técnicas que são orientados, em última instância, por propósitos competitivos, ou seja, a competição e a competitividade é que impulsionam as organizações a adequarem a produtividade, ao seu meio ambiente.

Conforme Bispo (2004), as variáveis econômicas e o jogo de poder exercido pelas empresas denotam-se como fatores implicantes à configuração do ambiente competitivo e à implantação do conceito de administração estratégica.

Ansof (1965), requer dois estilos de administração estratégica:

a) o primeiro estilo considera quando as mudanças não são bem aceitas, quando se recomenda a minimização dos efeitos desses desvios, tendo sempre como balizamento, resultados em que o fato real fosse diferente do esperado.

b) o segundo estilo é focado no comportamento do empreendedor.

Para a organização, a mudança é desejada, amplamente desejada e a satisfação é a meta. A administração estratégica é utilizada para realinhar os desvios de trajetórias que são geradas pelos riscos e oportunidades que os mercados oferecem. Considerando o exposto, observa-se que se trata de uma atividade típica da liderança, pois parte da capacidade do empreendedor, em tornar real sua visão.

A cooptação é instrumento valioso e segundo Porter (1985, p.15) "a vantagem competitiva é o coração da performance de uma empresa em mercados competitivos". E este posicionamento defendido é sintetizado no fato de muitas empresas falirem em função da dificuldade que as mesmas têm em traduzir o conceito amplo de estratégia competitiva em ações específicas que resultem para as empresas gerar e manter vantagem competitiva, explicando, dessa forma, a interseção entre a formulação e a implementação de estratégias. Daí a cooptação como agente coadjuvante e estratégico nas mais variadas configurações na busca incessante de domínio, poder e competitividade empresarial. 


\section{A Ética e a Cooptação}

Ponchirolli (2007) coloca que a ética tornou-se um dos temas mais trabalhados no pensamento administrativo, já que as pessoas começam a perceber que não é possível perpetuar a coorporação em ações sem ética. Dessa forma, a ética conquista, torna possível e permite a tentativa de obtenção de êxito.

\section{Questões ideológicas entre a Ética Organizacional e a Cooptação}

Weaver (1993), rediscute o real objetivo, a efetividade e o conteúdo do código de ética, expondo os aspectos de compliance e instrumento de legitimação que desenhavam os códigos até então, observando que estes tem papéis múltiplos, nem sempre coerentes com os papéis da organização, sendo preciso entender as condições nas quais as empresas os adotam. Weaver (1993) apresenta quatro bases intencionais para a implantação do código de ética: a) em benefício da atitude ética, como fim em si mesmo; o único modo de o código ser bem sucedido, considerando-se que há uma linha tênue entre comprometimento real com a ética e um código instrumental de valores, com segundas intenções; b) em resposta à requisição de um stakeholder específico; c) em atenção aos aspectos do ambiente social, como discriminação e bem-estar social; d) em direção da ética às condições do ambiente de negócios ou à dinâmica organizacional interna; ás reestruturações e mudanças organizacionais.

Assim, conforme acima descrito, exceto na hipótese de introdução do código, esse seria ferramenta de gestão de fato, para construir o controle organizacional, mostrando-se como uma ferramenta de gestão supressora dos indivíduos.

\section{A Sobrevivência da Empresa, a Ética e a Cooptação}

A perpetuação corporativa deveria ser guiada pelos valores éticos, expressos nos códigos de ética. Valores éticos orientam a realidade prática e originam tomadas de ações éticas apenas em corporações em que os valores foram construídos juntamente com os colaboradores e disseminados com a participação dos mesmos. Tais valores de fato impregnam o fator humano da entidade, passando a integrar a cultura da instituição. A construção é feita de estágio por estágio dessa relação. O documento, código de ética, sozinho não possui a capacidade de formar comportamentos éticos. Ademais, trata-se de um processo contínuo. É oportuno implementar uma constante discussão em todos os níveis hierárquicos da organização.

\section{Cenários Conflitantes: Ética X Cooptação}

Segundo Katz e Kahn (1978), a classificação das organizações como sistemas sociais abertos, dinâmicos e em constante relação com seu ambiente, faz com que o processo de mudança signifique a própria sobrevivência da organização, na medida em que ela se adapta às exigências do meio e, ao mesmo tempo, seja fonte para o desenvolvimento 
econômico, social e político da sociedade, evidenciando uma influência em ambos os lados nas relações entre a organização e o segmento em que atua.

Dessa forma, existe possibilidade de distanciamento de tempo entre a ética discriminada nos seus códigos e a ação concreta de suas decisões, que, embasadas nas diretrizes, podem conduzir à cooptação. Weaver (1993) define código de ética como documento formal distinto, que especifica obrigações éticas conscientes para a conduta organizacional, só existindo se for formulado com o propósito único de ser guiado por padrões morais para condutas éticas.

\section{Conclusão}

A cooptação é um fenômeno social, isto é, algo que emerge ou expressa ou resulta das múltiplas relações que estabelecemos cotidianamente, sejam pessoais ou empresariais.

O que se pode observar na fundamentação que a cooptação está intimamente ligada a ética empresarial, no papel de oposição, afetando, inclusive a saúde física e psíquica dos funcionários, uma vez que a cooptação e a ética podem afetar a tomada de decisão na empresa.

A cooptação se opõe sutilmente à ética, uma vez que as pessoas não aceitam o uso coercivo do poder, sobretudo veladamente. A missão primeira da empresa é tornar melhor a vida de todas as pessoas nela envolvidas. É fundamental a divulgação do valor da liberdade e do distanciamento da cooptação. Isso tem ocasionado um hiato entre a adoção de um novo discurso gerencial de pessoas e a sua efetiva aplicação, provocando a ocorrência do dilema organizacional, conhecido como contradições do discurso versus a prática. 


\section{Referências}

ARRUDA, Maria Cecília Coutinho de. Fundamentos de ética empresarial e economia. 2. ed. São Paulo: Atlas, 2003.

ANSOFF, L H. Corporate strategy: an analytic approach to business policy for growth and expansion. New York: McGraw-Hill, 1965

ANTUNES, José Pinto. A Produção sob o regime da empresa, São Paulo, Buchatsky, 1973.

BISPO, C. M., Clusters. Alianças e vantagem competitiva sob a interveniência da construção da base de recursos: a estratégia do setor de confecções de Cianorte-PR. Dissertação de Mestrado. PUC-PR, Curitiba PR: 2004.

CASTORIADIS, C. A instituição imaginária da sociedade. 3. ed. Rio de Janeiro:Paz e Terra, 1982.

CHANLAT, A. Prefácio. In: CHANLAT, J-F. et al. O indivíduo na organização: dimensões esquecidas. 3. ed. São Paulo: Atlas, 1996. v. 01. p. 17-20.

CHANLAT, A.; BÉDARD, R. Palavras: a ferramenta do executivo. In: CHANLAT, J-F. et al. O indivíduo na organização : dimensões esquecidas. 3. ed. São Paulo: Atlas,1996. v. 01. p. 125-148.

CHANLAT, J. F. Por uma antropologia da condição humana nas organizações. In: CHANLAT, J-F. et al. O indivíduo na organização : dimensões esquecidas. 3. ed. SãoPaulo: Atlas, 1996. v. 01. p. 21-45.

DEJOURS, C. Uma nova visão do sofrimento nas organizações. In: CHANLAT, J-F. et al. O indivíduo na organização : dimensões esquecidas. 3. ed. São Paulo: Atlas, 1996. v.01. p. 149-174.

. Conferências brasileiras: identidade, reconhecimento e transgressão no trabalho. São Paulo: Fundap: EAESP/FGV, 1999(a).

. O fator humano. 2. ed. Rio de Janeiro: Editora FGV, 1999(b).

DOZ, Yves L.; HAMEL, Gary. A vantagem das alianças: a arte de criar valor através de parcerias. Rio de Janeiro: Qualitymark, 2000.

ENRIQUEZ, E. Organização em análise . Petrópolis: Vozes, 1997(a).

. Os desafios éticos nas organizações modernas. Revista de Administração de Empresas, São Paulo, v. 37, n. 02, p. 06-17, abr.jun. 1997(b).

O indivíduo preso na armadilha da estrutura estratégica. Revista de Administração de Empresas, São Paulo, v. 37, n. 01, p. 18-29, jan./mar. 1997(c).

FARIA, J. H. de; MENEGHETTI, F. K. O seqüestro da subjetividade e as novas formas de controle psicológico no trabalho: uma abordagem crítica ao modelo toyotista de produção. In: Encontro da Associação Nacional de Pós-Graduação e Pesquisa em Administração, 25., 2001, Campinas. Anais ... Campinas: ANPAD, 2001.

KATZ, D.; Kahn, R.L. Psicologia social das organizações. São Paulo: Atlas, 1978.

MOREIRA, Joaquim Manhães (1999). A Ética empresarial no Brasil, São Paulo, Pioneira. 
. A Ética empresarial e o novo código civil .Disponível na internet. www.eticaempresarial.com.br/index Acessado a 27 setembro 2011. Pioneira, 1998.

PANCHIROLLI, Osmar Ética e responsabilidade social empresarial Disponível na internet.http://books.google.com.br/books Acessado a 18 outubro 2011. Juruá, 2007.

PORTER, M. E. Como as forças competitivas moldam a estratégia. In: Montgomery, C. A.; Porter, M. E. Estratégia: a busca da vantagem competitiva. 3. ed. Rio de Janeiro: Campos (1979), 1998b.

ROBBINS, Stephen P. Administração: mudanças e perspectivas. São Paulo: Saraiva, 2001.

TEIXEIRA, Nelson Gomes. A ética no mundo da empresa, São Paulo : Pioneira, 1998.

WEAVER, G. R. Corporate codes of ethics: purpose, process and content issues. Business and Society. CA, v. 32, n. 1, p. 44-58, Spring, 1993. 